\title{
Opioid-induced constipation: a narrative review of therapeutic options in clinical management
}

\author{
Kordula Lang-Illievich and Helmar Bornemann-Cimenti \\ Department of Anesthesiology and Intensive Care Medicine, Medical University of Graz, Graz, Austria
}

\begin{abstract}
Pain therapy often entails gastrointestinal adverse events. While opioids are effective drugs for pain relief, the incidence of opioid-induced constipation (OIC) varies greatly from $15 \%$ to as high as $81 \%$. This can lead to a significant impairment in quality of life, often resulting in discontinuation of opioid therapy. In this regard, a good doctor-patient relationship is especially pivotal when initiating opioid therapy. In addition to a detailed history of bowel habits, patient education regarding the possible gastrointestinal side effects of the drugs is crucial. In addition, the bowel function must be regularly evaluated for the entire duration of treatment with opioids. Furthermore, if the patient has preexisting constipation that is well under control, continuation of that treatment is important. In the absence of such history, general recommendations should include sufficient fluid intake, physical activity, and regular intake of dietary fiber. In patients of OIC with ongoing opioid therapy, the necessity of opioid use should be critically reevaluated in terms of an with acceptable quality of life, particularly in cases of non-cancer pain. If opioids must be continued, lowering the dose may help, as well as changing the type of opioid. If these measures do not suffice, the next step for persistent OIC is the administration of laxatives. If these are ineffective as well, treatment with peripherally active $\mu$-opioid receptor antagonists should be considered. Enemas and irrigation are emergency measures, often used as a last resort.
\end{abstract} (Korean J Pain 2019; 32: 69-78)

Key Words: Constipation; Dietary fiber; Enema; Exercise; Habits; Incidence; Laxatives; Narcotic antagonists; Opioid analgesics; Pain management; Pharmaceutical preparations; Quality of life.

\section{INTRODUCTION}

While opioids are effective in managing moderate-to-severe pain, drug-associated side effects are the chief reason for discontinuing opioid therapy in as many as $18.9 \%$ of $\mathrm{pa}^{-}$ tients [1]. Even as gastrointestinal adverse events are a common consequence of pain therapy [2], opioid-induced constipation (OIC), in particular, may lead to discontinuation of opioid therapy due to a significant impairment in quality of life.

In addition to the discomfort OIC causes the individual, there is a socioeconomic dimension as well. A recent

Received August 24, 2018. Revised January 2, 2019. Accepted January 14, 2019.

Correspondence to: Helmar Bornemann-Cimenti

Department of Anesthesiology and Intensive Care Medicine, Medical University of Graz, Auenbruggerplatz 29, 8036 Graz, Austria

Tel: +43-316-385-81103, Fax: +43-316-385-13852, E-mail: helmar.bornemann@medunigraz.at

ORCID: https://orcid.org/0000-0002-1201-3752

(a) This is an open-access article distributed under the terms of the Creative Commons Attribution Non-Commercial License (http:// creativecommons.org/licenses/by-nc/4.0/), which permits unrestricted non-commercial use, distribution, and reproduction in any medium, provided the original work is properly cited.

(c) The Korean Pain Society, 2019 
large-scale analysis from Denmark revealed that healthcare costs for patients with OIC were $25 \%$ higher than for those without the side effect [3].

Various therapies for OIC, both non-pharmacologic and pharmacologic, have been suggested. The latter category, notably, has had numerous innovations in recent years. The aim of this narrative review is to provide an overview of the available treatment options for OIC.

\section{MAIN BODY}

\section{Epidemiology}

The reported incidence of OIC varies greatly, from $15 \%$ to as high as $81 \%$ [4-7]. A possible explanation for this wide range is the lack of a standard definition for OIC. A systematic review noted that while only one-third of the studies on OIC stated the diagnostic criteria clearly, others used definitions based on differing symptoms without considering information about current or past opioid therapy or preexisting constipation. Of the included studies, 37\% relied exclusively on objective parameters such as stool frequency, even as the same proportion of studies included additional subjective parameters such as incomplete emptying [8].

In order to establish standardized diagnostic criteria for OIC and to facilitate comparison across studies, an international expert panel suggested a definition encompassing possible preexisting constipation, differences in bowel habits, as well as individual differences in the severity of opioid-related side effects, including reduced frequency, increased straining, harder stool consistency and incomplete evacuation [8].

Other authors have suggested the term "opioid-exacerbated constipation" specifically to address the exacerbation of preexisting constipation by opioid use [9], but this is not yet a commonly used expression.

\section{Diagnosis}

The lack of specific assessment tools is cited as one of the reasons for the frequent underestimation of the prevalence of OIC and the resulting inadequate management of the condition [10]. To address this issue, a multidisciplinary group of experts [11] evaluated the following survey instruments:
1) Patient assessment of constipation-symptoms (PACSYM) [12]

2) Patient assessment of constipation-quality of life (PAC-QOL) [13]

3) Stool Symptom Screener (SSS) [14]

4) Bowel Function Index (BFI) [15]

5) Bowel Function Diary (BF-diary) [16]

While the 11-point BF-diary was developed in accordance with the US Food and Drug Administration (FDA) guidelines, the BFI and the PAC-SYM are the most commonly used instruments in clinical practice. However, the consensus statement of the panel favored the BFI [11], which by virtue of its simplicity, can be regularly used in clinical practice to monitor changes in the severity of OIC, while the other questionnaires are rather complex to be used routinely. The BFI rates each of three dimensions: ease of defecation, feeling of incomplete emptying, and personal assessment of constipation, using a numerical analog scale to give a score between 0 and 100. If the arithmetic mean of these three scores is $>30$, treatment is recommended [15].

\section{Pathophysiology}

Opioid receptors are pervasive in the submucosa and mucosa of the gastrointestinal tract [4]. Activation of local $\mu$-receptors reduces gastric, intestinal, pancreatic, and biliary secretions [17], while stimulation of $\mu$-receptors of neurons in the myenteric and submucosal plexus inhibits peristalsis and increases the resting tone as well as non-propulsive motility of the gut, not least due to diminished release of the prokinetic agent, acetylcholine [4,18].

Activation of $\kappa$-opioid receptors leads to a reduction in propulsive contractions of the duodenum and jejunum as well as increased tone in the pyloric and ileocecal valves [19]. Data on the influence of $\delta$-opioid receptors on the human gastrointestinal tract are lacking.

Animal studies have demonstrated that the central effects of opioids may also influence gut motility. Intravenous morphine has been shown to extend intestinal transit time, suggesting an effect on autonomic centers in the central nervous system that control intestinal motility [20]. In addition to the normal physiologic influence of opioid receptors on the intestines, it should be noted that genetic polymorphisms of these receptors contribute to the unpredictable severity of gastrointestinal side effects [21]. 


\section{Traditional management}

Until quite recently, recommendations for the management of OIC were based on anecdotal evidence or expert opinion, particularly by analogy from the successful treatment of other forms of constipation [9]. Rigorous research has only been carried out in recent years, triggered primarily by the development of newer pharmaceuticals. Reliable evidence for the use of non-pharmacologic and general measures is very limited.

\section{1) General measures}

When opioid therapy is initiated, it is important to inform patients about OIC as a possible side effect. Regular enquiry into bowel habits including stool frequency and consistency as well as discomfort during defecation will allow prompt diagnosis and management, if $\mathrm{OIC}$ were to occur [6]. A recent large-scale analysis of a database of more than 100,000 patient-provider conversations revealed that patient education was largely insufficient in a majority of cases with only 1 in 10 patients with OIC discussing the problem with the healthcare provider. Furthermore, it was found that specific action was recommended only in a disconcerting one third of these cases [22].

Conventionally, non-pharmacologic measures are frequently recommended at the beginning of opioid therapy. Although not supported by any clinical studies, these recommendations are based on treatments that are found to be effective in other constipation disorders [20], such as increased fluid intake, even though this measure does not provide relief in the absence of dehydration [23]. On the other hand, physical activity, especially frequent vigorous exercise, is associated with a lower risk of developing constipation [23]. A study of patients with chronic constipation who did not exercise regularly showed that moderate physical activity significantly improved intestinal symptoms and colon transit time [24].

According to evidence-based guidelines, increased dietary fiber intake is useful in patients suffering from OIC [25]. Dietary fiber consists of high-molecular-weight food constituents that cannot be degraded by intestinal enzymes and therefore, remain in the bowel lumen increasing stool volume. Fiber is classified as soluble and non-soluble. Generally, soluble fiber is more beneficial in the treatment of constipation. However, it is important to note that suf- ficient hydration and regular physical activity are essential for dietary fiber to be effective [26]. In addition, slow transit times associated with OIC may reduce the efficacy of this measure. Nevertheless, considering the advantages of dietary fiber, including wide availability, low cost, and lack of toxicity irrespective of the source, a therapeutic trial examining the effect of graded doses of fiber in OIC is warranted [19].

However, since lifestyle modifications often prove inadequate in the treatment of $\mathrm{OIC}$, other types of therapy often need to be added.

\section{2) Laxatives}

Laxatives are a varied group of preparations that act by a number of different mechanisms:

(1) Liquefaction of the stool by inhibiting the absorption of water (lactulose, galactose)

(2) Liquefaction of the stool by increasing intraluminal osmotic pressure (polyethylene glycol, sorbitol, mannitol, Epsom salt)

(3) Increased stool volume by bulk-forming agents in conjunction with adequate hydration (psyllium, wheat bran, agar)

(4) Stimulation of intestinal peristalsis with active secretion of electrolytes and water to increase intestinal filling pressure and stimulate increased activity of the longitudinal intestinal musculature (senna, castor oil, bisacodyl, sodium picosulfate)

(5) Stool softening (enemas, glycerol suppositories)

Little data on the treatment of OIC with laxatives is available, with almost no evidence from placebo-controlled or comparative studies [27]. A systematic review assessing the side effects and efficacy of various laxatives was severely limited by the lack of consistency in the definition of OIC [28]. Therefore, guidelines recommending prescription of laxatives as prophylaxis or therapy for OIC in patients with both cancer and non-cancer pain [11,29,30], are essentially based on low-level evidence [9]. Macrogol is the only laxative to have been evaluated in a placebo-controlled trial in OIC treatment, therefore it is recommended as a first choice [31].

Despite the absence of high-level evidence in their favor, inconsistent results (satisfactory effect observed in only about 50\% of patients [32]), and need for frequent dose adjustments or changing of the laxatives themselves, 
advantages such as cost-effectiveness, safety, and easy availability make the case for the choice of laxatives as first-line therapy. Combination therapy with laxatives combined with different mechanisms of action seems reasonable [29].

\section{3) Opioid rotation}

All opioids carry a risk of gastrointestinal dysfunction of varying severity. However, given their varied biochemical properties, rotating between hydrophilic opioids (such as morphine, oxycodone, or hydromorphone) and lipophilic ones (such as fentanyl, buprenorphine, or methadone) may be beneficial, especially in view of a greater number of hydrophilic receptors in the gastrointestinal tract [33]. This requires careful calculation of equivalent doses in order to prevent over- or under-dosing. Development of tolerance, in this context, is beneficial since it will entail decreasing the calculated dose $[34,35]$ which may be reflected as remission of OIC symptoms. Although Mercadante et al. [36] showed that it was successful in balancing analgesia and side effects in $80 \%$ of patients in the palliative care setting, opioid rotation in clinical practice lacks concrete supporting evidence despite its widespread use.

A few studies have directly compared the incidence of gastrointestinal side effects of different opioids delivered through various routes. Allan et al. [37] found that in opioid-naive patients with chronic low back pain, transdermal fentanyl was associated with significantly less constipation than was sustained-release morphine. A metaanalysis by Tassinari et al. [38] that included three randomized trials comparing the incidence of constipation with transdermal opioids (fentanyl and buprenorphine) versus slow-release morphine for cancer pain revealed that a statistically significant difference was clearly evident in favor of transdermal opioid administration (odds ratio $=0.38$, $P<0.001$ ). A Cochrane review and a network analysis of opioids for cancer patients showed that a lower rate of constipation was associated with transdermal opioids $[39,40]$.

\section{(1) Tapentadol}

Approved by the FDA in 2008, tapentadol is a relatively new drug in the opioid market. It is characterized by a synergistic mode of action, as it is both a $\mu$ agonist and a norepinephrine-reuptake inhibitor [41]. Preclinical studies have demonstrated that although the affinity of tapentadol for $\mu$-receptors is 50 times lower than that of morphine, the equianalgesic doses differed only two- to three-fold [42]. This might contribute to the favorable side effect profile of tapentadol. In regard to constipation, tapentadol was shown to be superior to oxycodone or other opioids for both cancer and non-cancer pain [43-45].

\section{(2) Combination of oxycodone and naloxone}

Oxycodone, a $\mu$ and $\kappa-$ receptor agonist, is commercially available in a $2: 1$ combination with naloxone, a competitive $\mu, \kappa$, and $\delta$-receptor antagonist. The bioavailability of orally administered naloxone is less than $3 \%$ due to high first-pass metabolism so that, within certain dose limits, naloxone remains intraluminal and blocks opioid receptors in the gut, thereby reducing gastrointestinal side effects without antagonizing the analgesic effect of oxycodone and preventing the onset of withdrawal symptoms. However, for the oxycodone/naloxone combination to be effective in this manner, adequate hepatic function is essential [46].

A maximum daily dose of oxycodone/naloxone of $160 / 80 \mathrm{mg}$ is recommended by the manufacturer, since the local intraluminal effect of naloxone can no longer be demonstrated if this dose is exceeded. One case report, however, stated that a dose of 180/90 mg achieved good pain control without side effects [47].

This oxycodone/naloxone combination has been shown to be associated with lower rates of OIC. The BFI score and laxative consumption, often used as surrogates for efficacy, were both lower in patients taking oxycodone/naloxone [34]. In patients with refractory OIC, defined as the regular use of at least two laxatives, oxycodone/naloxone was associated with a significant improvement in constipation compared to oxycodone alone [48]. A recent meta-analysis showed that the combination was effective in reducing constipation in both cancer and non-cancer pain [49].

An economic analysis showed that oxycodone/naloxone was cost-saving [50], and a head-to-head comparison of oxycodone/naloxone with tapentadol showed comparable gastrointestinal effects [51]. An interesting study by Poulsen et al. [52] compared oxycodone/naloxone versus oxycodone plus macrogol. Patients taking oxycodone/ naloxone had significantly better relaxation of the internal 
anal sphincter, emphasizing the distinct differences in the modes of action of each combination.

\section{4) Prokinetics}

\section{(1) Neostigmine}

Neostigmine is an acetylcholinesterase inhibitor that increases the concentration of neurotransmitter acetylcholine in the synaptic cleft, thereby enhancing prokinetic activity. The recommended doses in the literature vary considerably $(0.35-4 \mathrm{mg} / \mathrm{d})$, as does the reported effectiveness. This has been attributed to prokinetic overstimulation resulting in marked inhibition of motility. Therefore, the administration of low doses $(0.5-1 \mathrm{mg}$ in $24 \mathrm{~h}$ ) is recommended [53]. Only a single case report of the use of neostigmine in the treatment of OIC could be found [54].

\section{(2) Prucalopride}

Prucalopride is a serotonin receptor agonist with a selective high-affinity for intestinal 5-hydroxy tryptamine 4 (5-HT4) receptors, which have prokinetic effects, promoting peristalsis and defecation. At therapeutic doses, it does not inhibit human ether-a-go-go-related gene (hERG) potassium channels, (which are known to play a pivotal role in long-QT syndrome) and has no proarrhythmic effect, unlike the structurally related cisapride (which has been withdrawn from the market) $[55,56]$. While one placebo-controlled study failed to show a statistically significant increase in spontaneous bowel movements, even as $52 \%$ of participants reported adverse reactions [57], another trial reported significant improvement of OIC with prucalopride [58].

\section{Newer treatment options}

\section{1) Lubiprostone}

Lubiprostone is a selective chloride channel activator that promotes the transport of chloride ions into the intestine through chloride channel 2 (CIC-2) by a naloxone-independent, i.e. non-opioid, mechanism. This results in enhanced paracellular fluid secretion, gut motility, and defecation $[59,60]$.

A multi-center trial of lubiprostone for OIC in patients with non-cancer pain showed a statistically significant improvement in stool consistency and constipation compared to a placebo. Additionally, no significant differences in the consumption of rescue medication for pain were documented [61]. Similar results were reported in another placebo-controlled study which also included patients with OIC and non-cancer pain [62]. A more recent study, however, failed to reproduce these positive findings [63]. In a pooled analysis of all three phase- 3 studies, lubiprostone had significantly lower success rates in patients taking methadone. This might be explained by an interaction of methadone and lubiprostone affecting the $\mathrm{ClC}-2$ channel that had been documented in a preclinical investigation [60].

\section{2) Peripherally active $\mu$-opioid receptor antagonists}

Peripherally active $\mu$-opioid receptor antagonists (PAMORAs) are designed to antagonize the intestinal activity of opioids while preserving their systemic effect. Although the efficacy of these drugs has been demonstrated in placebo-controlled studies, their cost-effectiveness in comparison to laxatives remains unclear.

\section{(1) Methylnaltrexone}

The naltrexone derivative methylnaltrexone acts as a competitive $\mu$-receptor antagonist and, to a much lesser extent, antagonizes $\kappa$ and $\delta$-receptors as well. As a highly polar quaternary amine with a pronounced hydrophilic character, methylnaltrexone cannot cross the blood-brain barrier into the high-fat tissue of the brain. This allows methylnaltrexone to act peripherally as an antagonist of the $\mu$-opioid receptors in tissues such as the digestive tract, selectively exerting an effect there without opposing the opioid analgesic effect in the central nervous system [64]. Earlier, only a subcutaneous formulation was available, but in 2016, the FDA approved an oral form.

A review summarizing six studies, despite being limited by large heterogeneity in study design, demonstrated the clear superiority of methylnaltrexone over a placebo, wherein the number needed to treat was 3 [57]. Furthermore, a network meta-analysis reported that methylnaltrexone performed better in treating OIC than lubiprostone, naloxegol, oral methyl naltrexone, or prucalopride [65]. 
The recommended daily dose of methylnaltrexone is $0.15 \mathrm{mg} / \mathrm{kg}$, with higher doses being reportedly associated with the need for a higher opioid dose for adequate analgesia. Involvement of peripheral $\mu$-opioid receptors in the analgesic effect of the opioids appears to be responsible [66].

\section{(2) Naloxegol}

Naloxegol is a pegylated naloxone derivative that acts by selectively blocking peripheral $\mu$-receptors in the gastrointestinal tract. The pegylation reduces passive diffusion across membranes such that naloxegol does not cross the blood-brain barrier into the central nervous system. The analgesic effect of concurrently administered opioids is therefore not affected.

In patients with non-cancer pain, clear effects of naloxegol were achieved with doses of 25 and $50 \mathrm{mg} / \mathrm{d}$ compared to a placebo. While the dose of $12.5 \mathrm{mg} / \mathrm{d}$ produced inconsistent results [67], that of $5 \mathrm{mg} / \mathrm{d}$ did not show beneficial effects [68]. In a study in the palliative care setting, a fixed dose of $8 \mathrm{mg}$ or $12 \mathrm{mg}$ (depending on weight, with a $62-\mathrm{kg}$ cut-off value) was associated with significantly improved bowel function and a favorable safety profile [69].

A recent retrospective analysis of 1,300 patients revealed that $25 \mathrm{mg}$ naloxegol had similar efficacy in treating OIC regardless of the maintenance opioid type, dose, or duration of opioid use at baseline [70].

\section{(3) Alvimopan}

Alvimopan is an orally administered $\mu$-receptor antagonist that cannot cross the blood-brain barrier. Although it has already been used in the United States for postoperative ileus, this drug has not yet been approved in other parts of the world. A double-blind, placebo-controlled study among 518 patients with OIC showed that a dose of 0.5 mg administered twice daily improved gut motility as measured by the number of spontaneous defecations (72\% with alvimopan vs. $48 \%$ with a placebo, $P<0.001$ ). A comparable study of 485 participants failed to demonstrate a significant effect [71]. Although an influence on the analgesic effect of the administered opioids could not be determined [72], long-term use of alvimopan is reportedly associated with an increased risk of myocardial infarction [73].

\section{(4) Naldemedine}

Naldemedine is the newest product on the market and was recently approved for the treatment of OIC [74]. Pharmacologically, it is a peripherally selective $\mu$-opioid receptor antagonist. A number of trials evaluating the efficacy of naldemedine in the treatment of OIC [75-78] were reviewed by Murphy and Sheridan [79]. They concluded that $0.2 \mathrm{mg} / \mathrm{d}$ of naldemedine was effective in reducing constipation and improving stool frequency in patients with non-cancer pain treated with opioids.

\section{Procedures to empty the rectum and sigmoid colon}

Even as the use of suppositories, enemas, and irrigation may be necessary in the management of acute OIC that has not responded to other measures, these procedures have not been investigated by means of randomized controlled trials [80].

\section{Proposed algorithm for clinical management}

A number of algorithms and guidelines have been proposed in the clinical management of OIC $[12,81,82]$.

As noted earlier, patient education regarding the possible gastrointestinal side effects is crucial when initiating opioid therapy. A careful history of bowel habits and function should be elicited on a regular basis for the entire duration of treatment with opioids, so that $\mathrm{OIC}$ can be detected and managed at the earliest point. In view of this, a good doctor-patient relationship with clear communication is indispensable, as is open and active discussion with patients to help them overcome any embarrassment they might have in reporting such details.

Based on this review of OIC therapeutics, the following algorithm is suggested (Fig. 1). If the patient has preexisting constipation that is well under control, that treatment should be continued. In the absence of such history, general recommendations should include drinking sufficient amount of fluids daily, engaging in physical activity, and regular intake of dietary fiber.

In patients already on opioid therapy who have OIC, the necessity of the opioid use should be critically reevaluated in terms of an acceptable quality of life, particularly in cases of non-cancer pain. If opioids must be continued, lowering the dose may help, as can opioid rotation. 

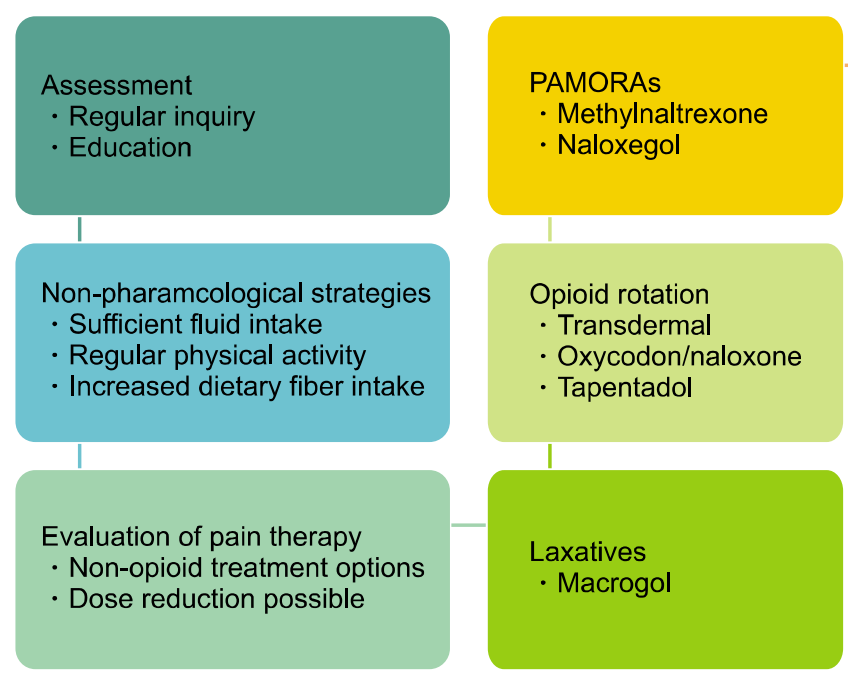

If these measures do not suffice, the next step for persistent OIC is the administration of laxatives. If these are ineffective as well, treatment with PAMORAs should be considered. Enemas and irrigation are emergency measures, often used as a last resort.

\section{CONCLUSIONS}

Though opioids are effective drugs for pain relief, opioid therapy can lead to a significant impariment in quality of life. Various treatment options should be considred to reduce the OIC.

\section{CONFLICT OF INTEREST}

No potential conflict of interest relevant to this article was reported.

\section{REFERENCES}

1. Häuser W, Bernardy K, Maier C. Long-term opioid therapy in chronic noncancer pain: a systematic review and meta-analysis of efficacy, tolerability and safety in open-label extension trials with study duration of at least 26 weeks. Schmerz 2015; 29: 96-108.

2. Kalso E, Edwards JE, Moore RA, McQuay HJ. Opioids in chronic non-cancer pain: systematic review of efficacy and safety. Pain 2004; 112: 372-80.

3. Søndergaard J, Christensen HN, Ibsen R, Jarbø| DE, Kjellberg $J$. Healthcare resource use and costs of opioid-induced constipation among non-cancer and cancer patients on opioid therapy: a nationwide register-based cohort study in

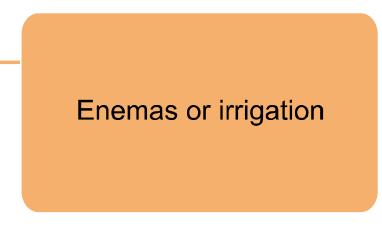

Fig. 1. Clinical management of opioid induced constipation. PAMORAs: peripherally active $\mu$-opioid receptor antagonists.

Denmark. Scand J Pain 2017; 15: 83-90.

4. Camilleri M. Opioid-induced constipation: challenges and therapeutic opportunities. Am J Gastroenterol 2011; 106: 835-42.

5. Ketwaroo GA, Cheng V, Lembo A. Opioid-induced bowel dysfunction. Curr Gastroenterol Rep 2013; 15: 344.

6. Nelson AD, Camilleri M. Chronic opioid induced constipation in patients with nonmalignant pain: challenges and opportunities. Therap Adv Gastroenterol 2015; 8: 206-20.

7. Tafelski S, Beuthauser T, Bellin F, Reuter E, Fritzsche T, West $C$, et al. Incidence of constipation in patients with outpatient opioid therapy. Schmerz 2016; 30: 158-65. German.

8. Gaertner J, Siemens W, Camilleri M, Davies A, Drossman DA, Webster LR, et al. Definitions and outcome measures of clinical trials regarding opioid-induced constipation: a systematic review. J Clin Gastroenterol 2015; 49: 9-16.

9. Brenner DM, Stern E, Cash BD. Opioid-related constipation in patients with non-cancer pain syndromes: a review of evidence-based therapies and justification for a change in nomenclature. Curr Gastroenterol Rep 2017; 19: 12.

10. Ducrotté P. Milce J, Soufflet C, Fabry C. Prevalence and clinical features of opioid-induced constipation in the general population: a French study of 15,000 individuals. United European Gastroenterol J 2017; 5: 588-600.

11. Argoff CE, Brennan MJ, Camilleri M, Davies A, Fudin J, Galluzzi KE, et al. Consensus recommendations on initiating prescription therapies for opioid-induced constipation. Pain Med 2015; 16: 2324-37.

12. Frank $L$, Kleinman $L$, Farup $C$, Taylor $L$, Miner $P \mathrm{Jr}$. Psychometric validation of a constipation symptom assessment questionnaire. Scand J Gastroenterol 1999; 34: $870-7$

13. Marquis $P$, De La Loge C, Dubois D, McDermott A, Chassany $\mathrm{O}$. Development and validation of the Patient Assessment of Constipation Quality of Life questionnaire. 
Scand J Gastroenterol 2005; 40: 540-51.

14. Coyne KS, Currie BM, Holmes WC, Crawley JA. Assessment of a stool symptom screener and understanding the opioidinduced constipation symptom experience. Patient 2015; 8: 317-27.

15. Rentz AM, van Hanswijck de Jonge P, Leyendecker P, Hopp M. Observational, nonintervention, multicenter study for validation of the Bowel Function Index for constipation in European countries. Curr Med Res Opin 2011; 27: 35-44.

16. Camilleri M, Rothman M, Ho KF, Etropolski M. Validation of a bowel function diary for assessing opioid-induced constipation. Am J Gastroenterol 2011; 106: 497-506.

17. Sobczak M, Sałaga M, Storr MA, Fichna J. Physiology, signaling, and pharmacology of opioid receptors and their ligands in the gastrointestinal tract: current concepts and future perspectives. J Gastroenterol 2014; 49: 24-45.

18. Brock C, Olesen SS, Olesen AE, Frøkjaer JB, Andresen T, Drewes AM. Opioid-induced bowel dysfunction: pathophysiology and management. Drugs 2012; 72: 1847-65.

19. Dorn S, Lembo A, Cremonini F. Opioid-induced bowel dysfunction: epidemiology, pathophysiology, diagnosis, and initial therapeutic approach. Am J Gastroenterol Suppl 2014; 2: $31-7$.

20. Galligan JJ, Burks TF. Centrally mediated inhibition of small intestinal transit and motility by morphine in the rat. J Pharmacol Exp Ther 1983; 226: 356-61.

21. Finco G, Pintor M, Sanna D, Orrù G, Musu M, De Conno $F$, et al. Is target opioid therapy within sight? Minerva Anestesiol 2012; 78: 462-72.

22. Vallerand AH, Hendry S, Baldys E, Hu Y, Datto C. Analysis of patient-provider interactions regarding the burden and treatment of opioid-induced constipation in adults with chronic noncancer pain. Pain Med 2018 Aug 13 [Epub]. Available at https://doi.org/10.1093/pm/pny 151.

23. Müller-Lissner SA, Kamm MA, Scarpignato C, Wald A. Myths and misconceptions about chronic constipation. Am J Gastroenterol 2005; 100: 232-42.

24. De Schryver AM, Keulemans YC, Peters HP, Akkermans LM, Smout AJ, De Vries WR, et al. Effects of regular physical activity on defecation pattern in middle-aged patients complaining of chronic constipation. Scand J Gastroenterol 2005; 40: 422-9.

25. Andresen V, Enck P. Frieling T, Herold A, Ilgenstein P, Jesse $N$, et al. S2k guideline for chronic constipation: definition, pathophysiology, diagnosis and therapy. Z Gastroenterol 2013; 51: 651-72.

26. Suares NC, Ford AC. Systematic review: the effects of fibre in the management of chronic idiopathic constipation. Aliment Pharmacol Ther 2011; 33: 895-901.

27. Ruston T, Hunter K, Cummings G, Lazarescu A. Efficacy and side-effect profiles of lactulose, docusate sodium, and sennosides compared to PEG in opioid-induced con- stipation: a systematic review. Can Oncol Nurs J 2013; 23: 236-46.

28. Rauck RL, Hong KJ, North J. Opioid-induced constipation survey in patients with chronic noncancer pain. Pain Pract 2017; 17: 329-35.

29. Caraceni A, Hanks G, Kaasa S, Bennett Ml, Brunelli C, Cherny $\mathrm{N}$, et al. Use of opioid analgesics in the treatment of cancer pain: evidence-based recommendations from the EAPC. Lancet Oncol 2012; 13: e58-68.

30. Manchikanti L, Abdi S, Atluri S, Balog CC, Benyamin RM, Boswell MV, et al. American Society of Interventional Pain Physicians (ASIPP) guidelines for responsible opioid prescribing in chronic non-cancer pain: part 2--guidance. Pain Physician 2012; 15 (3 Suppl): S67-116.

31. Freedman MD, Schwartz HJ, Roby R, Fleisher S. Tolerance and efficacy of polyethylene glycol 3350/electrolyte solution versus lactulose in relieving opiate induced constipation: a double-blinded placebo-controlled trial. J Clin Pharmacol 1997; 37: 904-7.

32. Müller-Lissner $\mathbf{S}$. Myth about causes and treatment of constipation. MMW Fortschr Med 2013; 155: 56-7.

33. Leppert W. Emerging therapies for patients with symptoms of opioid-induced bowel dysfunction. Drug Des Devel Ther 2015; 9: 2215-31.

34. Knotkova H, Fine PG, Portenoy RK. Opioid rotation: the science and the limitations of the equianalgesic dose table. J Pain Symptom Manage 2009; 38: 426-39.

35. Michaeli K, Liebhauser M, Bornemann-Cimenti H, Wejbora M, Sandner-Kiesling A. Opioid dose ratios in pain therapy: an evidence-based contemplation. Eur $J$ Anaesthesiol $2010 ; 27: 25-6$.

36. Mercadante S, Ferrera P, Villari P, Casuccio A, Intravaia G, Mangione S. Frequency, indications, outcomes, and predictive factors of opioid switching in an acute palliative care unit. J Pain Symptom Manage 2009; 37: 632-41.

37. Allan L, Richarz U, Simpson K, Slappendel R. Transdermal fentanyl versus sustained release oral morphine in strong-opioid naïve patients with chronic low back pain. Spine (Phila Pa 1976) 2005; 30: 2484-90.

38. Tassinari D, Sartori S, Tamburini E, Scarpi E, Raffaeli W, Tombesi $\mathrm{P}$, et al. Adverse effects of transdermal opiates treating moderate-severe cancer pain in comparison to long-acting morphine: a meta-analysis and systematic review of the literature. J Palliat Med 2008; 11: 492-501.

39. Ahn JS, Lin J, Ogawa S, Yuan C, O'Brien T, Le BH, et al. Transdermal buprenorphine and fentanyl patches in cancer pain: a network systematic review. J Pain Res 2017; 10: 1963-72.

40. Hadley G, Derry S, Moore RA, Wiffen PJ. Transdermal fentanyl for cancer pain. Cochrane Database Syst Rev 2013; (10): CD010270.

41. Chang EJ, Choi EJ, Kim KH. Tapentadol: can it kill two birds 
with one stone without breaking windows? Korean J Pain 2016; 29: 153-7.

42. Tzschentke TM, Christoph T, Kögel B, Schiene K, Hennies $H H$, Englberger W, et al. (-)-(1R,2R)-3-(3-dimethylamino1-ethyl-2-methyl-propyl)-phenol hydrochloride (tapentadol $\mathrm{HCl}$ ): a novel mu-opioid receptor agonist/norepinephrine reuptake inhibitor with broad-spectrum analgesic properties. J Pharmacol Exp Ther 2007; 323: 265-76.

43. Mercadante $S$. The role of tapentadol as a strong opioid in cancer pain management: a systematic and critical review. Curr Med Res Opin 2017; 33: 1965-9.

44. Lange B, von Zabern D, Elling C, Dubois C. Efficacy and safety of tapentadol prolonged release for moderateto-severe chronic osteoarthritis knee pain: a pooled analysis of two double-blind, randomized, placebo- and oxycodone controlled release-controlled studies. Curr Med Res Opin 2017; 33: 1413-22.

45. Xiao JP, Li AL, Feng BM, Ye Y, Wang GJ. Efficacy and safety of tapentadol immediate release assessment in treatment of moderate to severe pain: a systematic review and metaanalysis. Pain Med 2017; 18: 14-24.

46. Leppert W. Oxycodone/naloxone in the management of patients with pain and opioid-induced bowel dysfunction. Curr Drug Targets 2014; 15: 124-35.

47. Bujedo BM. Treatment of failed back surgery syndrome in a forty-three-year-old man with high-dose oxycodone/naloxone. Anesth Pain Med 2015; 5: e21009.

48. Koopmans G, Simpson K, De Andrés J, Lux EA, Wagemans M, Van Megen $Y$. Fixed ratio (2:1) prolonged-release oxycodone/naloxone combination improves bowel function in patients with moderate-to-severe pain and opioid-induced constipation refractory to at least two classes of laxatives. Curr Med Res Opin 2014; 30: 2389-96

49. Morlion BJ, Mueller-Lissner SA, Vellucci R, Leppert W, Coffin BC, Dickerson SL, et al. Oral prolonged-release oxycodone/ naloxone for managing pain and opioid-induced constipation: a review of the evidence. Pain Pract 2018; 18: 647-65.

50. Rychlik R, Viehmann K, Daniel D, Kiencke P, Kresimon J. Pain management and costs of a combination of oxycodone+ naloxone in low back pain patients. In: Pain management - current issues and opinions. Edited by Racz G. Rijeka, Intech. 2012, pp 307-20.

51. Ueberall MA, Mueller-Schwefe GH. Efficacy and tolerability balance of oxycodone/naloxone and tapentadol in chronic low back pain with a neuropathic component: a blinded end point analysis of randomly selected routine data from 12-week prospective open-label observations. J Pain Res 2016; 9: 1001-20.

52. Poulsen JL, Brock C, Grønlund D, Liao D, Gregersen H, Krogh $\mathrm{K}$, et al. Prolonged-release oxycodone/naloxone improves anal sphincter relaxation compared to oxycodone plus macrogol 3350. Dig Dis Sci 2017; 62: 3156-66.

53. Fruhwald S, Holzer P, Metzler $H$. Gastrointestinal motility in acute illness. Wien Klin Wochenschr 2008; 120: 6-17.

54. Papa P, Turconi L. Neostigmine for the treatment of gastrointestinal atony: a report of one case. J Palliat Med 2011; 14: 1270-3.

55. Klivinyi C, Bornemann-Cimenti $H$. Pain medication and long QT syndrome. Korean J Pain 2018; 31: 3-9.

56. Chapman $H$, Pasternack $M$. The action of the novel gastrointestinal prokinetic prucalopride on the HERG K+ channel and the common T897 polymorph. Eur J Pharmacol 2007; 554: 98-105.

57. Ford AC, Brenner DM, Schoenfeld PS. Efficacy of pharmacological therapies for the treatment of opioidinduced constipation: systematic review and meta-analysis. Am J Gastroenterol 2013; 108: 1566-74; quiz 1575.

58. Sloots CE, Rykx A, Cools M, Kerstens R, De Pauw M. Efficacy and satety of prucalopride in patients with chronic noncancer pain suffering from opioid-induced constipation. Dig Dis Sci 2010; 55: 2912-21.

59. Holder RM, Rhee D. Novel oral therapies for opioid-induced bowel dysfunction in patients with chronic noncancer pain. Pharmacotherapy 2016; 36: 287-99.

60. Cuppoletti J, Chakrabarti J, Tewari K, Malinowska DH. Methadone but not morphine inhibits lubiprostone-stimulated $\mathrm{Cl}-$ currents in T84 intestinal cells and recombinant human CIC-2, but not CFTR Cl- currents. Cell Biochem Biophys 2013; 66: 53-63.

61. Jamal MM, Adams AB, Jansen JP, Webster LR. A randomized, placebo-controlled trial of lubiprostone for opioid-induced constipation in chronic noncancer pain. Am J Gastroenterol 2015; 110: 725-32.

62. Cryer B, Katz S, Vallejo R, Popescu A, Ueno R. A randomized study of lubiprostone for opioid-induced constipation in patients with chronic noncancer pain. Pain Med 2014; 15: 1825-34.

63. Spierings EL, Drossman DA, Cryer B, Mazen Jamal M, Losch-Beridon T, Mareya SM, et al. Efficacy and safety of lubiprostone in patients with opioid-induced constipation: phase 3 study results and pooled analysis of the effect of concomitant methadone use on clinical outcomes. Pain Med 2018; 19: 1184-94.

64. Zacny JP, Wroblewski K, Coalson DW. Methylnaltrexone: its pharmacological effects alone and effects on morphine in healthy volunteers. Psychopharmacology (Berl) 2015; 232: $63-73$.

65. Sridharan K, Sivaramakrishnan G. Drugs for treating opioid-induced constipation: a mixed treatment comparison network meta-analysis of randomized controlled clinical trials. J Pain Symptom Manage 2018; 55: 468-479.e1.

66. Jagla C, Martus P, Stein C. Peripheral opioid receptor blockade increases postoperative morphine demands: a 
randomized, double-blind, placebo-controlled trial. Pain 2014; 155: 2056-62.

67. Chey WD, Webster L, Sostek M, Lappalainen J, Barker PN, Tack J. Naloxegol for opioid-induced constipation in patients with noncancer pain. N Engl J Med 2014; 370: 2387-96.

68. Webster L, Dhar S, Eldon M, Masuoka L, Lappalainen J, Sostek M. A phase 2, double-blind, randomized, placebocontrolled, dose-escalation study to evaluate the efficacy, safety, and tolerability of naloxegol in patients with opioidinduced constipation. Pain 2013; 154: 1542-50.

69. Bull J, Wellman CV, Israel RJ, Barrett AC, Paterson C, Forbes WP. Fixed-dose subcutaneous methylnaltrexone in patients with advanced illness and opioid-induced constipation: results of a randomized, placebo-controlled study and open-label extension. J Palliat Med 2015; 18: 593-600.

70. Nalamachu S, Gudin J, Datto C, Coyne K, Poon JL, Hu Y. Efficacy and safety of naloxegol for opioid-induced constipation assessed by specific opioid medication, opioid dose, and duration of opioid use. J Opioid Manag 2018; 14: 211-21.

71. Irving G, Pénzes J, Ramjattan B, Cousins M, Rauck R, Spierings EL, et al. A randomized, placebo-controlled phase 3 trial (Study SB-767905/013) of alvimopan for opioidinduced bowel dysfunction in patients with non-cancer pain. J Pain 2011; 12: 175-84.

72. Jansen JP, Lorch D, Langan J, Lasko B, Hermanns K, Kleoudis CS, et al. A randomized, placebo-controlled phase 3 trial (Study SB-767905/012) of alvimopan for opioidinduced bowel dysfunction in patients with non-cancer pain. J Pain 2011; 12: 185-93.

73. Gyawali B, Hayashi N, Tsukuura H, Honda K, Shimokata T, Ando Y. Opioid-induced constipation. Scand J Gastroenterol 2015; 50: 1331-8.

74. Markham A. Naldemedine: first global approval. Drugs 2017; 77: 923-7.

75. Hale M, Wild J, Reddy J, Yamada T, Arjona Ferreira JC.
Naldemedine versus placebo for opioid-induced constipation (COMPOSE-1 and COMPOSE-2): two multicentre, phase 3, double-blind, randomised, parallel-group trials. Lancet Gastroenterol Hepatol 2017; 2: 555-64.

76. Webster LR, Yamada T, Arjona Ferreira JC. A phase 2b, randomized, double-blind placebo-controlled study to evaluate the efficacy and safety of naldemedine for the treatment of opioid-induced constipation in patients with chronic noncancer pain. Pain Med 2017; 18: 2350-60.

77. Katakami N, Harada T, Murata T, Shinozaki K, Tsutsumi M, Yokota T, et al. Randomized phase III and extension studies of naldemedine in patients with opioid-induced constipation and cancer. J Clin Oncol 2017; 35: 3859-66.

78. Katakami N, Oda K, Tauchi K, Nakata K, Shinozaki K, Yokota $T$, et al. Phase $\| \mathrm{b}$, randomized, double-blind, placebocontrolled study of naldemedine for the treatment of opioid-induced constipation in patients with cancer. J Clin Oncol 2017; 35: 1921-8.

79. Murphy JA, Sheridan EA. Evidence based review of pharmacotherapy for opioid-induced constipation in noncancer pain. Ann Pharmacother 2018; 52: 370-9.

80. Bove A, Bellini M, Battaglia E, Bocchini R, Gambaccini D, Bove $\mathrm{V}$, et al. Consensus statement AlGO/SICCR diagnosis and treatment of chronic constipation and obstructed defecation (part II: treatment). World J Gastroenterol 2012; 18: 4994-5013.

81. Müller-Lissner S, Bassotti G, Coffin B, Drewes AM, Breivik $H$, Eisenberg E, et al. Opioid-induced constipation and bowel dysfunction: a clinical guideline. Pain Med 2017; 18: 183763.

82. Drewes AM, Munkholm P, Simrén M, Breivik H, Kongsgaard UE, Hatlebakk JG, et al. Definition, diagnosis and treatment strategies for opioid-induced bowel dysfunction-Recommendations of the Nordic Working Group. Scand J Pain 2016; 11: 111-22. 